\title{
A novel prohibitin-binding compound induces the mitochondrial apoptotic pathway through NOXA and BIM upregulation
}

\author{
Cristina Moncunill-Massaguer ${ }^{1}$, José Saura-Esteller ${ }^{1}$, Alba Pérez-Perarnau ${ }^{1}$, \\ Claudia Mariela Palmeri ${ }^{1}$, Sonia Núñez-Vázquez ${ }^{1}$, Ana M. Cosialls ${ }^{1}$, Diana M. \\ González-Gironès ${ }^{1}$, Helena Pomares ${ }^{1}$, Anne Korwitz ${ }^{2}$, Sara Preciado ${ }^{3}$, Fernando \\ Albericio ${ }^{3,4,5}$, Rodolfo Lavilla ${ }^{3,6}$, Gabriel Pons ${ }^{1}$, Thomas Langer ${ }^{2}$, Daniel Iglesias- \\ Serret $^{1, *}$ and Joan Gil ${ }^{1, *}$ \\ ${ }^{1}$ Departament de Ciències Fisiològiques II, Universitat de Barcelona-Institut d'Investigació Biomèdica de Bellvitge (IDIBELL), \\ L'Hospitalet de Llobregat, Catalunya, Spain \\ ${ }^{2}$ Institute for Genetics and Cologne Excellence Cluster on Cellular Stress Responses in Aging-Associated Diseases (CECAD), \\ University of Cologne, Cologne, Germany \\ ${ }^{3}$ Barcelona Science Park and CIBER-BBN, Networking Centre on Bioengineering, Biomaterials and Nanomedicine, Barcelona, \\ Spain \\ ${ }^{4}$ Institute for Research in Biomedicine Barcelona, Barcelona, Spain \\ ${ }^{5}$ Department of Organic Chemistry, University of Barcelona, Barcelona, Spain \\ ${ }^{6}$ Laboratory of Organic Chemistry, Faculty of Pharmacy, University of Barcelona, Barcelona, Spain \\ * These authors share senior co-authorship
}

Correspondence to: Joan Gil, email: jgil@ub.edu

Keywords: apoptosis, prohibitins, BCL-2 family members, mitochondria, cancer

Received: April 29, $2015 \quad$ Accepted: September 30, 2015 Published: October 19, 2015

This is an open-access article distributed under the terms of the Creative Commons Attribution License, which permits unrestricted use, distribution, and reproduction in any medium, provided the original author and source are credited.

\section{ABSTRACT}

We previously described diaryl trifluorothiazoline compound 1a (hereafter referred to as fluorizoline) as a first-in-class small molecule that induces p53independent apoptosis in a wide range of tumor cell lines. Fluorizoline directly binds to prohibitin 1 and 2 (PHBs), two proteins involved in the regulation of several cellular processes, including apoptosis. Here we demonstrate that fluorizoline-induced apoptosis is mediated by PHBs, as cells depleted of these proteins are highly resistant to fluorizoline treatment. In addition, BAX and BAK are necessary for fluorizolineinduced cytotoxic effects, thereby proving that apoptosis occurs through the intrinsic pathway. Expression analysis revealed that fluorizoline induced the upregulation of Noxa and Bim mRNA levels, which was not observed in PHB-depleted MEFs. Finally, $\mathrm{Noxa}^{-/-} / \mathrm{Bim}^{-/-}$MEFs and NOXA-downregulated HeLa cells were resistant to fluorizolineinduced apoptosis. All together, these findings show that fluorizoline requires PHBs to execute the mitochondrial apoptotic pathway.

\section{INTRODUCTION}

Resistance to cell death is one of the hallmarks of cancer development, and it compromises the efficacy of conventional anti-cancer agents [1]. Hence, there is need for the development of novel apoptosis-inducing compounds as potential therapies for cancer. In a previous report we described the synthesis of a class of small molecules with an unprecedented fluorinated thiazoline scaffold as novel pro-apoptotic compounds [2].
Interestingly, the diaryl trifluorothiazoline compound 1a (Figure 1a), hereafter referred to as fluorizoline, triggered apoptosis through a p53-independent mechanism, which is highly relevant as half of all cancers acquire mutations in p53 during the malignant transformation [3]. In addition, we identified prohibitin 1 and 2 (PHBs) as proteins selectively binding to fluorizoline [2].

PHBs are evolutionary conserved, ubiquitously expressed proteins that are required for cellular proliferation, development, and the functional integrity 
of mitochondria [4-6]. Consistently, depletion of PHBs leads to an impairment in embryonic development in Caenorhabditis elegans and mice [7-10]. PHBs are predominantly found in mitochondria, but they have also been identified in other cell compartments, including the plasma membrane and the nucleus $[4,11]$. Within the inner mitochondrial membrane (IMM), PHB1 and PHB2 interact with each other to form large heteromeric ringlike complexes, which presumably serve as membrane scaffolds [6, 12]. Cells depleted of PHBs show fragmented mitochondria with an altered ultrastructure, as well as marked degradation of L-OPA1 [10, 13], a mitochondrial dynamin-like GTPase that mediates mitochondrial fusion and maintains cristae structure $[14,15]$. In addition, PHBs have been linked to oxidative stress, as their absence induces the production of reactive oxygen species [16-19], and their overexpression protects against oxidative stress $[18,20,21]$. Loss of PHBs leads to impaired proliferation $[10,13,22]$ and increased sensitivity to apoptotic stimuli $[10,11,18,23-25]$. Thus, PHBs play a key role in the maintenance of the functional integrity of mitochondria, which ultimately allows proper cell and tissue homeostasis [4,6,26-28].

The role of PHBs in cancer remains controversial $[11,29]$. An anti-tumorigenic role for PHBs was reported in various tumor cell types [30-33]. In contrast, PHBs have been linked to tumor growth, resistance to chemotherapy and metastasis [11, 29, 34]. The requirement of PHBs for cell proliferation strongly indicates a potential role in cancer progression $[4,11,12,22,35]$. Along this line, overexpression of $\mathrm{PHB} 1$ results in a higher resistance to apoptosis in different types of cancer cells, while downregulation of PHBs renders cancer cells more susceptible to pro-apoptotic insults $[11,21,29,36]$, suggesting a pro-tumorigenic role of PHBs.

In view of the pleiotropic functions of $\mathrm{PHBs}$, these proteins emerge as highly interesting targets for the development of novel treatments for cancer [11, 29, 37]. In this regard, we propose that PHB-binding fluorizoline is a promising new agent due to its pro-apoptotic capacity.

Here we further dissect the mechanism by which fluorizoline induces apoptosis and demonstrate that this compound requires PHBs to increase Noxa and Bim expression and to trigger the mitochondrial apoptotic pathway.

\section{RESULTS}

\section{Fluorizoline requires the presence of prohibitins in order to induce apoptosis}

We previously reported that fluorizoline (Figure 1a) binds specifically to PHB1 and PHB2 [2]. To examine whether the pro-apoptotic effects of this compound require PHBs, we sought to analyze the response of PHB-deficient cells to fluorizoline treatment. To this end, we used $P h b 2^{f l f l}$ MEFs, in which Cre-recombinase transduction induces loss of the Phb2 gene [10]. PHBs are interdependent at the protein level, thus loss of PHB2 leads to the degradation of PHB1 [9, 10]. As a control, we used wild type (WT) MEFs, in which Cre-recombinase transduction does not modify PHB protein levels. Seventy-two hours after Cre-recombinase transduction, WT and $P h b 2^{f / f t}$ MEFs were treated with increasing doses of fluorizoline for $24 \mathrm{~h}$, and cell viability was analyzed by flow cytometry. While WT MEFs were sensitive to fluorizoline treatment, loss of PHBs conferred strong resistance to fluorizoline-induced apoptosis in Cre-

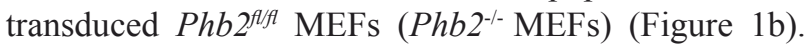
In contrast, both cell lines showed a similar response to Actinomycin D (ActD). Western blot analysis revealed that Cre-mediated depletion of Phb2 was accompanied by loss of PHB1 and L-OPA1 (Figure 1c), as previously described [10]. In addition, fluorizoline treatment led to cleavage of caspase 3 and poly ADP-ribose polymerase (PARP) in WT MEFs, thereby indicating induction of apoptosis. In contrast, the cleavage of these two proteins was clearly reduced in fluorizoline-treated $\mathrm{Phb}^{-/-} \mathrm{MEFs}$ (Figure 1c). Contrary to fluorizoline, ActD triggered similar cleavage of caspase 3 and PARP in WT and Phb2-/MEFs. Furthermore, disappearance of L-OPA1 forms was observed in fluorizoline- and ActD- treated WT MEFs.

Treatment with fluorizoline triggered apoptosis in WT and Phb2 fllt MEFs in a similar manner in the absence of Cre-recombinase (Supplementary Figure 1a). Accordingly, fluorizoline and ActD induced a similar processing of caspase 3, PARP, and L-OPA1 in WT and $P h b 2^{\text {flft }}$ MEFs (Supplementary Figure 1b). These findings demonstrate that the resistance observed in $\mathrm{Phb}^{-/-}$MEFs was not due to intrinsic insensitivity to apoptotic insults of the cell line but to the loss of PHBs.

In order to corroborate that lack of PHBs confers resistance to fluorizoline-induced apoptosis, $P h b 2$ levels were downregulated by siRNA transfection in $P h b 2^{\text {flft }}$ MEFs. Reduction of Phb2 resulted in decreases of PHB1 and L-OPA1 (Figure 1e). As expected, the pro-apoptotic effects of fluorizoline were blocked when PHBs were downregulated, as shown by flow cytometry and western blot analysis (Figure 1d-1e). These results were further confirmed by Phb2 siRNA transfection in WT MEFs (Supplementary Figure 1c-d). All together, these findings demonstrate that PHBs are necessary for fluorizolineinduced apoptosis.

Furthermore, we sought to analyze whether modulation of PHB expression levels affects the sensitivity to fluorizoline. To this end, PHBs were overexpressed in $P h b 2^{f l f l}$ MEFs and the response to fluorizoline was examined. Interestingly, fluorizoline efficiently triggered 
apoptosis in spite of PHB overexpression (Supplementary Figure 2a-b). Similar results were obtained by overexpressing PHBs in HeLa cells (Supplementary Figure 2c-d).

In addition, the pro-apoptotic effects of fluorizoline were analyzed in $P h b 2^{f / /}$ MEFs, which show lower levels of PHBs compared to $P h b 2^{f l f l}$ (Supplementary Figure $3 a)$. Cells were incubated with fluorizoline for $24 \mathrm{~h}$ and viability was analyzed by flow cytometry. Strikingly, $P h b 2^{f /-}$ and $P h b 2^{A / f l}$ clones displayed similar sensitivity to fluorizoline treatment (Supplementary Figure 3b). Taken together, these results show that the protein levels of PHBs do not strictly correlate with the sensitivity to fluorizoline. Resistance to fluorizoline can only be observed in the absence of PHBs.

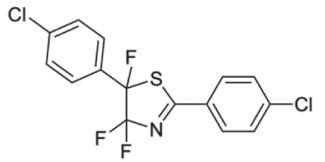

Fluorizoline (1a)

b
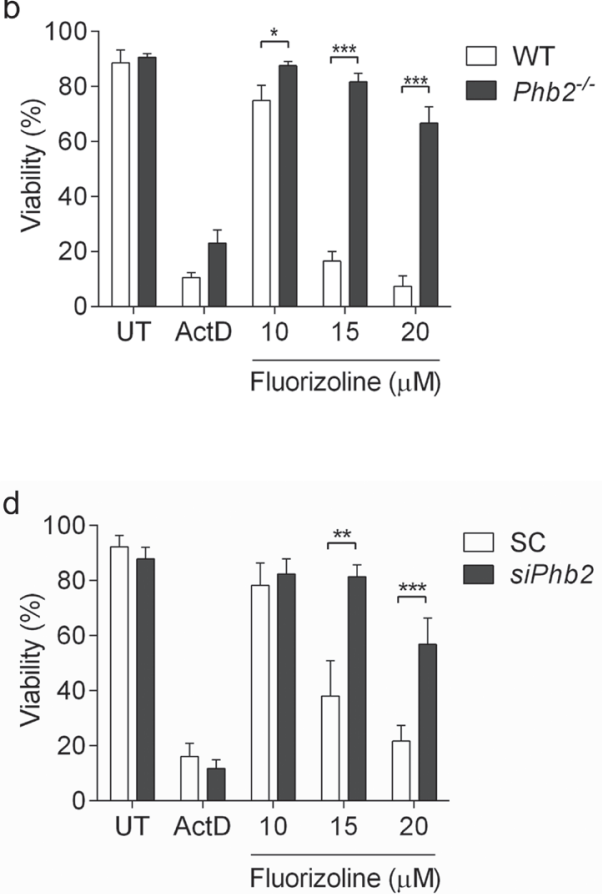

Fluorizoline induces mitochondrial fragmentation and cristae disorganization

Upon apoptosis induction with various stimuli, the mitochondrial network undergoes extensive fragmentation, along with cristae remodeling [38-41]. Interestingly, this phenotype was also observed upon loss of PHBs, which was attributed to the accelerated processing of L-OPA1 $[10,13]$. We sought to analyze mitochondrial morphology and ultrastructure after fluorizoline treatment. HeLa cells incubated with fluorizoline presented fragmented mitochondria that clustered around the nucleus (Figure 2a), as well as disarrangements of cristae, which appeared dilated and disorganized (Figure 2b). Higher magnification micrographs $(60,000 \mathrm{X})$ showed that incubation with fluorizoline induced partial or total loss of cristae, along with remodeling of the IMM into many separate vesicular

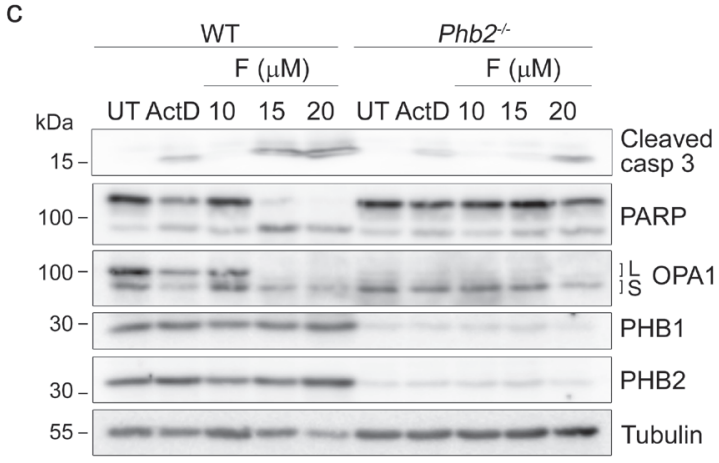

e
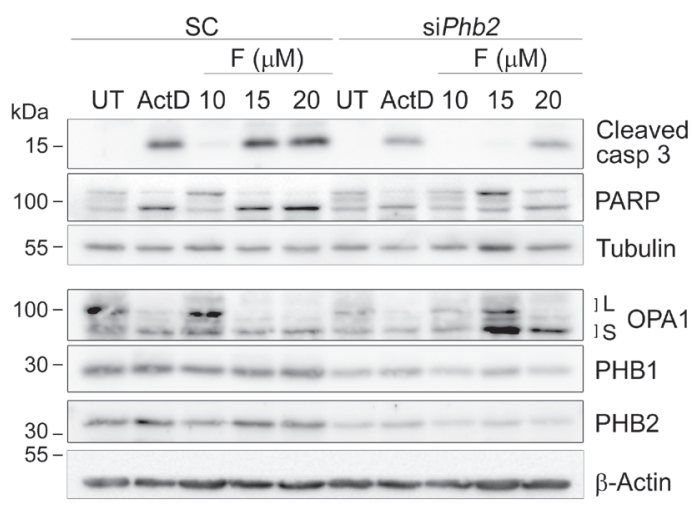

Figure 1: The presence of PHBs is required for fluorizoline-induced apoptosis. a. Chemical structure of fluorizoline (diaryl

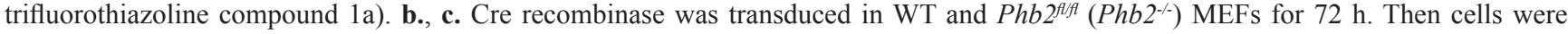
untreated (UT) or treated with either $0.15 \mu \mathrm{g} / \mathrm{mL}$ Actinomycin D (ActD) or increasing doses of fluorizoline (F) for $24 \mathrm{~h}$. d., e. $P h b 2^{f / f l} \mathrm{MEFs}$ were transfected with scramble (SC) or Phb2 (siPhb2) siRNA for $72 \mathrm{~h}$. Afterwards, cells were treated with either $0.15 \mu \mathrm{g} / \mathrm{mL}$ Actinomycin $\mathrm{D}$ (ActD) or increasing doses of fluorizoline (F) for $24 \mathrm{~h}$. b., d. Viability was measured by flow cytometry and it is expressed as the mean \pm $\operatorname{SEM}(n \geq 3)$ of the percentage of non-apoptotic cells (annexin V-negative). ${ }^{*} p<0.05,{ }^{* *} p<0.01,{ }^{* * *} p<0.001$. c., e. Protein levels were analyzed by western blot. Tubulin and $\beta$-Actin were used as a loading control. These are representative images of at least three independent experiments. 
and electron-lucent matrix compartments (Figure 2b). Therefore, these results show that fluorizoline treatment leads to mitochondrial fragmentation and cristae disorganization. These findings are consistent with the a
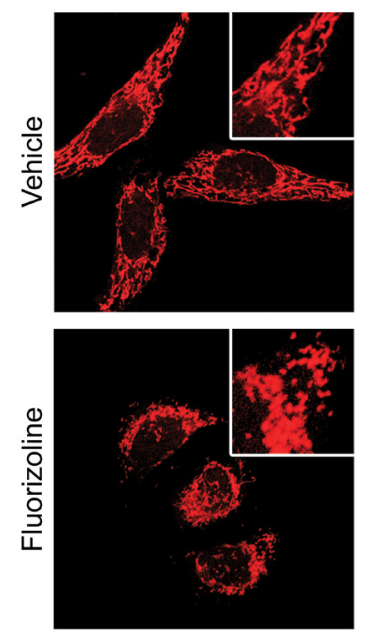

b
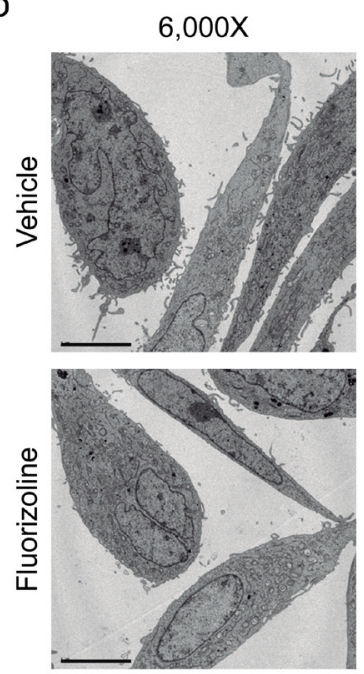

$20,000 x$
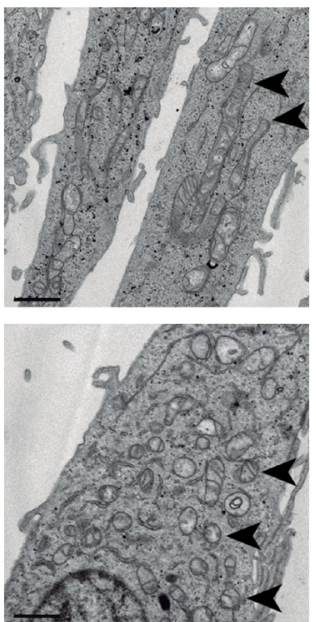

$60,000 x$
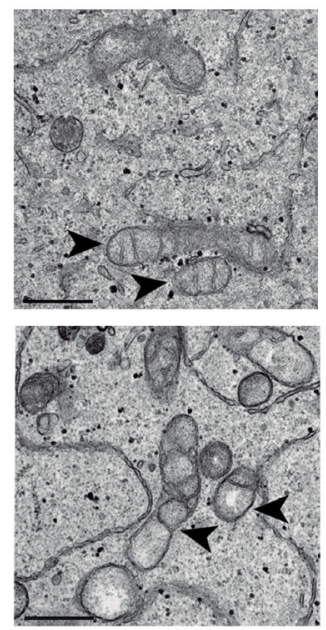

Figure 2: Treatment with fluorizoline induces changes in the mitochondrial morphology and ultrastructure. a. HeLa cells were treated with DMSO (vehicle) or $10 \mu \mathrm{M}$ fluorizoline for $4 \mathrm{~h}$. Mitochondria were stained with $100 \mathrm{nM}$ MitoTracker ${ }^{\circledR}$ Red CMXRos and imaged using a confocal microscope. b. HeLa cells were incubated with DMSO (vehicle) or $2 \mu \mathrm{M}$ fluorizoline for $24 \mathrm{~h}$ and changes in the mitochondrial morphology were visualized by transmission electron microscopy. Magnification at 6,000X (scale corresponding to 5 $\mu \mathrm{m}$ ), 20,000X (scale corresponding to $1 \mu \mathrm{m}$ ), and 60,000X (scale corresponding to $0.5 \mu \mathrm{m}$ ). Arrowheads indicate the mitochondria.

a

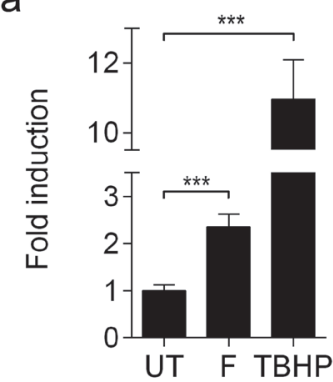

$\mathrm{C}$

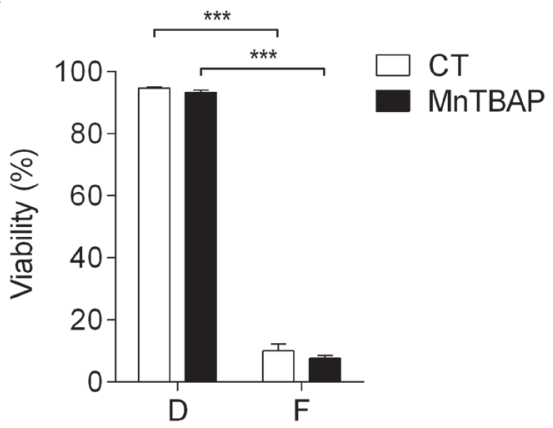

b

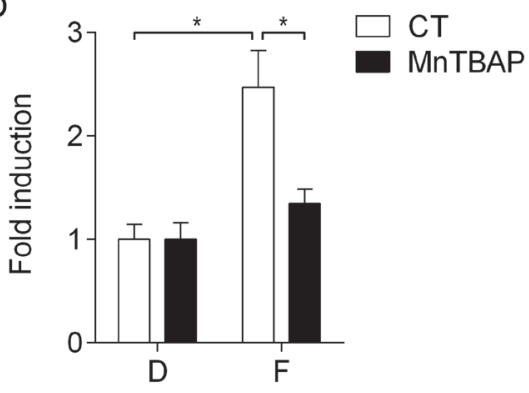

d

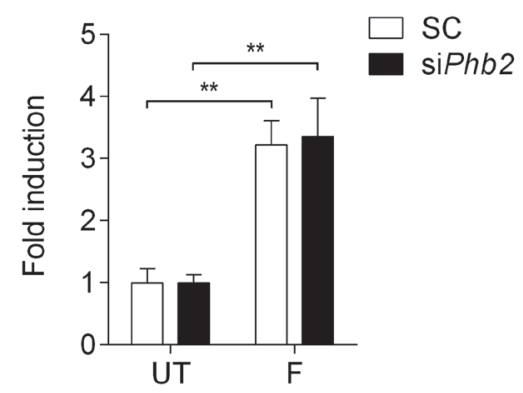

Figure 3: Fluorizoline induces ROS production independently of PHBs and apoptosis induction. a. Jurkat cells were untreated (UT), or treated with $10 \mu \mathrm{M}$ fluorizoline (F) for $1 \mathrm{~h}$ or $200 \mu \mathrm{M}$ tert-butyl hydroperoxide (TBHP) for $30 \mathrm{~min}$. b. Jurkat cells were untreated (CT) or pre-incubated with $150 \mu \mathrm{M}$ MnTBAP for $1 \mathrm{~h}$ and then treated with DMSO (D) or $10 \mu \mathrm{M}$ fluorizoline (F) for $1 \mathrm{~h}$. c. Jurkat cells were untreated (CT) or pre-incubated with $150 \mu \mathrm{M}$ MnTBAP for $1 \mathrm{~h}$ and then treated with DMSO (D) or $10 \mu \mathrm{M}$ fluorizoline (F) for $24 \mathrm{~h}$. Viability was measured by flow cytometry and it is expressed as the mean $\pm \operatorname{SEM}(n=3)$ of the percentage of non-apoptotic cells (annexin V-negative). d. $P h b 2^{t / f}$ MEFs were transfected with scramble (SC) or $P h b 2$ (siPhb2) siRNA for $72 \mathrm{~h}$. Cells were then untreated or treated with $20 \mu \mathrm{M}$ fluorizoline (F) for 1 hour. a., b., d. Superoxide anion and hydroxyl radical production was analyzed by flow cytometry using CellROX ${ }^{\circledR}$ Deep Red Reagent. Data show the mean values \pm SEM relative to the mean of the control (a, $\left.n=9 ; \mathrm{b}, n=3 ; \mathrm{d}, n=4\right) .{ }^{*} p$ $<0.05, * * p<0.01, * * * p<0.001$. 
capacity of fluorizoline to induce apoptosis and with PHBs being the target of this compound.

To analyze the role of OPA1 in fluorizoline-induced apoptosis, we overexpressed variant 1 of OPA1 lacking the $\mathrm{S} 1$ cleavage site (OPA1- $\Delta \mathrm{S} 1)$, a non-cleavable long form of OPA1 [42]. Strikingly, fluorizoline could efficiently induce apoptosis in the presence of OPA $1-\Delta \mathrm{S} 1$
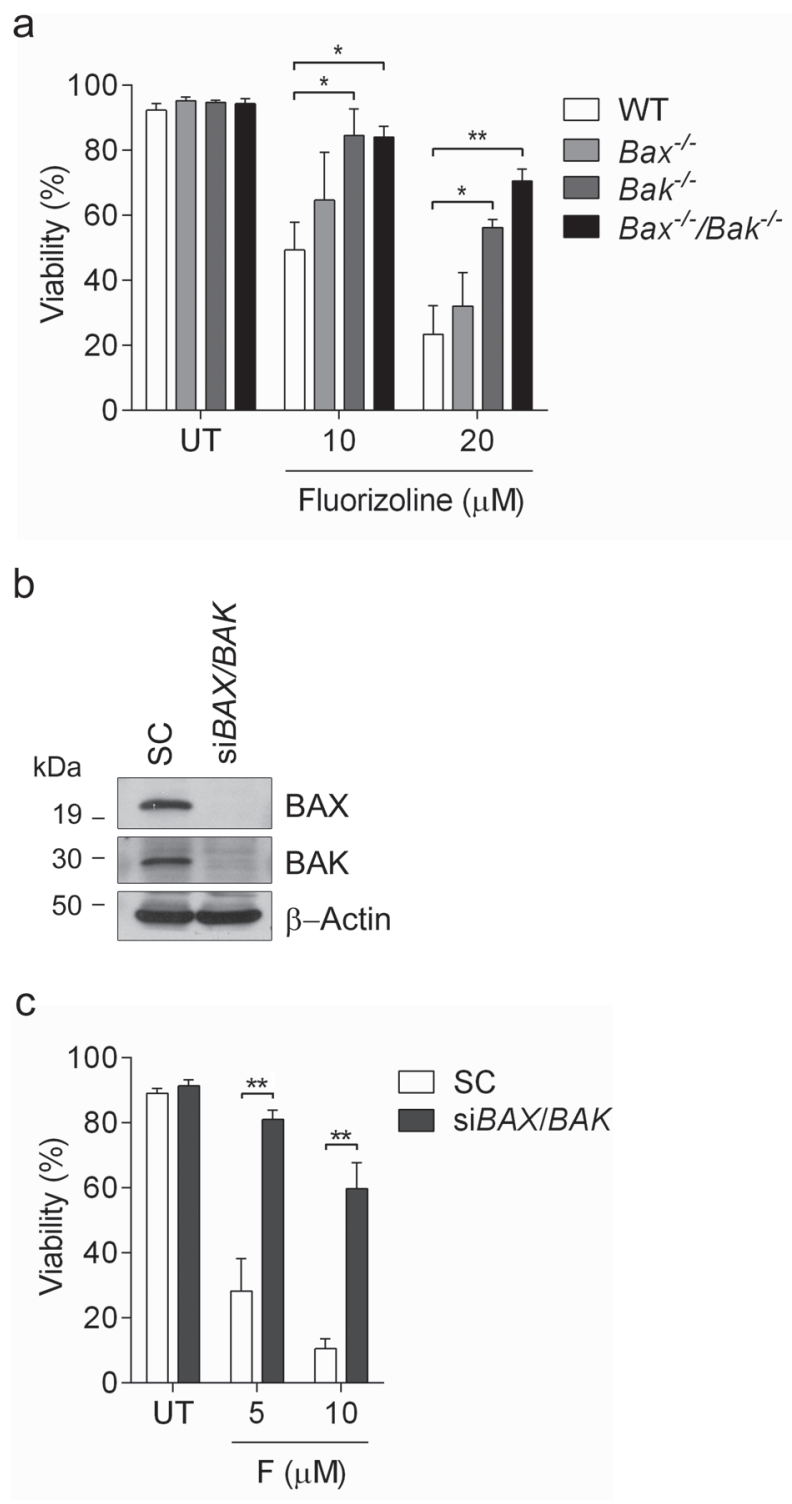

Figure 4: Fluorizoline-induced apoptosis occurs through the mitochondrial pathway in a BAX- and BAK-dependent manner. a. WT, Bax ${ }^{-/}, \mathrm{Bak}^{-/}$or $\mathrm{Bax}^{-1 /}$ $B a k^{-1-}$ MEFs were untreated (UT) or treated with 10 or $20 \mu \mathrm{M}$ fluorizoline for $24 \mathrm{~h}$. b., c. HeLa cells were transfected with scramble (SC) or $B A X$ and $B A K$ siRNA (si $B A X / B A K$ ) for $48 \mathrm{~h}$. b. The efficiency of gene silencing was validated by western blot. $\beta$-Actin was used as a loading control. This is a representative image of at least three independent experiments. c. HeLa cells were untreated (UT) or treated with 5 or $10 \mu \mathrm{M}$ fluorizoline $(\mathrm{F})$ for 24 h. a., c. Viability was measured by flow cytometry and it is expressed as the mean \pm SEM $(n \geq 3)$ of the percentage of non-apoptotic cells (annexin V-negative). ${ }^{*} p<0.05,{ }^{* *} p<0.01$.
(Supplementary Figure 4a-b), suggesting that the loss of L-OPA1 is not required for the pro-apoptotic effects of fluorizoline. To confirm these results, we used MEFs lacking OMA1, a mitochondrial protease that cleaves OPA1 in response to several stress insults [43-47]. Fluorizoline treatment triggered the loss of L-OPA1 in WT MEFs, while Oma1 ${ }^{-/}$MEFs maintained L-OPA1 forms even in the presence of fluorizoline. In contrast, WT and $\mathrm{Oma1}^{-/}$MEFs showed a similar response to fluorizoline (Supplementary Figure 4c-d). All together, these results prove that fluorizoline does not rely on stress-induced loss of L-OPA1 forms to induce apoptosis.

\section{Fluorizoline increases the production of reactive oxygen species independently of PHBs and apoptosis induction}

We analyzed the effects of fluorizoline on the mitochondrial membrane potential $(\Delta \Psi \mathrm{m})$ as an indicator of mitochondrial function. As apoptosis induction can affect $\Delta \Psi \mathrm{m}$ [39], it was important to analyze $\Delta \Psi \mathrm{m}$ before the onset of cell death. To this end, we used Jurkat cells, as previous results from our group showed that cytochrome $c$ was released from mitochondria after $8 \mathrm{~h}$ of fluorizoline treatment [2]. Interestingly, $8 \mathrm{~h}$ of fluorizoline treatment resulted only in a slight loss of $\Delta \Psi \mathrm{m}$ (Supplementary Figure 5), which suggests that it is a consequence of apoptosis induction.

In addition, we sought to analyze whether treatment with fluorizoline leads to generation of reactive oxygen species (ROS) by using CellROX ${ }^{\circledR}$ Deep Red reagent, which detects superoxide anion and hydroxyl radical. Jurkat cells showed increased ROS production upon treatment with fluorizoline for $1 \mathrm{~h}$ (Figure $3 \mathrm{a}$ ). In order to study the involvement of ROS in fluorizoline-induced apoptosis, we pre-treated cells with the SOD mimetic manganese (III)-tetrakis (4-benzoic acid) porphyrin (MnTBAP), which efficiently inhibited fluorizolineinduced ROS production (Figure 1d), while it could not revert the apoptotic effects of fluorizoline (Figure $3 \mathrm{c})$. Furthermore, we analyzed the production of ROS in Phb2-downregulated MEFs, which were resistant to fluorizoline-induced apoptosis (Figure 1a). Importantly, the absence of PHBs could not inhibit the generation of ROS induced by fluorizoline (Figure 3d). All together, these results demonstrate that fluorizoline does not require the generation of ROS to induce apoptosis.

\section{Fluorizoline induces the mitochondrial apoptotic pathway in a BAX/BAK-dependent manner}

The execution of apoptosis depends on the balance between pro- and anti-apoptotic BCL-2 family members $[48,49]$. BAX and BAK are two multidomain proapoptotic proteins whose activation leads to mitochondrial 
outer membrane permeabilization (MOMP) and the release of mitochondrial intermembrane proteins such as cytochrome $c$, two critical steps in the execution of apoptosis $[48,49]$. In order to evaluate the role of BAX and BAK in fluorizoline-induced apoptosis, we used $\mathrm{Bax}^{-/}, \mathrm{Bak}^{-/-}$and $\mathrm{Bax}^{-/ /} / \mathrm{Bak}^{-/-} \mathrm{MEF}$, which are resistant to multiple cell death stimuli that induce apoptosis through MOMP [50]. Importantly, fluorizoline triggered apoptosis in WT MEFs, while the absence of both BAX and BAK significantly prevented the cytotoxic effects of this compound (Figure 4a). Bax ${ }^{-/-}$MEFs were as sensitive to fluorizoline as WT MEFs, although $\mathrm{Bak}^{-/} \mathrm{MEFs}$ offered some resistance to the apoptosis induced by this compound.

To corroborate these results, HeLa cells were transiently depleted of these two pro-apoptotic proteins by siRNA transfection (Figure 4b). Consistently, depletion of $\mathrm{BAX}$ and $\mathrm{BAK}$ reduced the apoptotic response to fluorizoline treatment (Figure 4c).

To confirm the importance of the activation of the intrinsic apoptotic pathway, we used Jurkat cells overexpressing BCL- $\mathrm{X}_{\mathrm{L}}$ [51]. This is an anti-apoptotic member of the BCL-2 family, whose overexpression can block the intrinsic pathway of apoptosis [51, 52]. Fluorizoline was able to induce apoptosis in WT Jurkat cells, while overexpression of $\mathrm{BCL}_{\mathrm{L}} \mathrm{X}_{\mathrm{L}}$ conferred resistance to the pro-apoptotic effects of fluorizoline (Supplementary Figure 6a-b).

Although the lack of BAX and BAK conferred significant resistance to fluorizoline treatment, cell
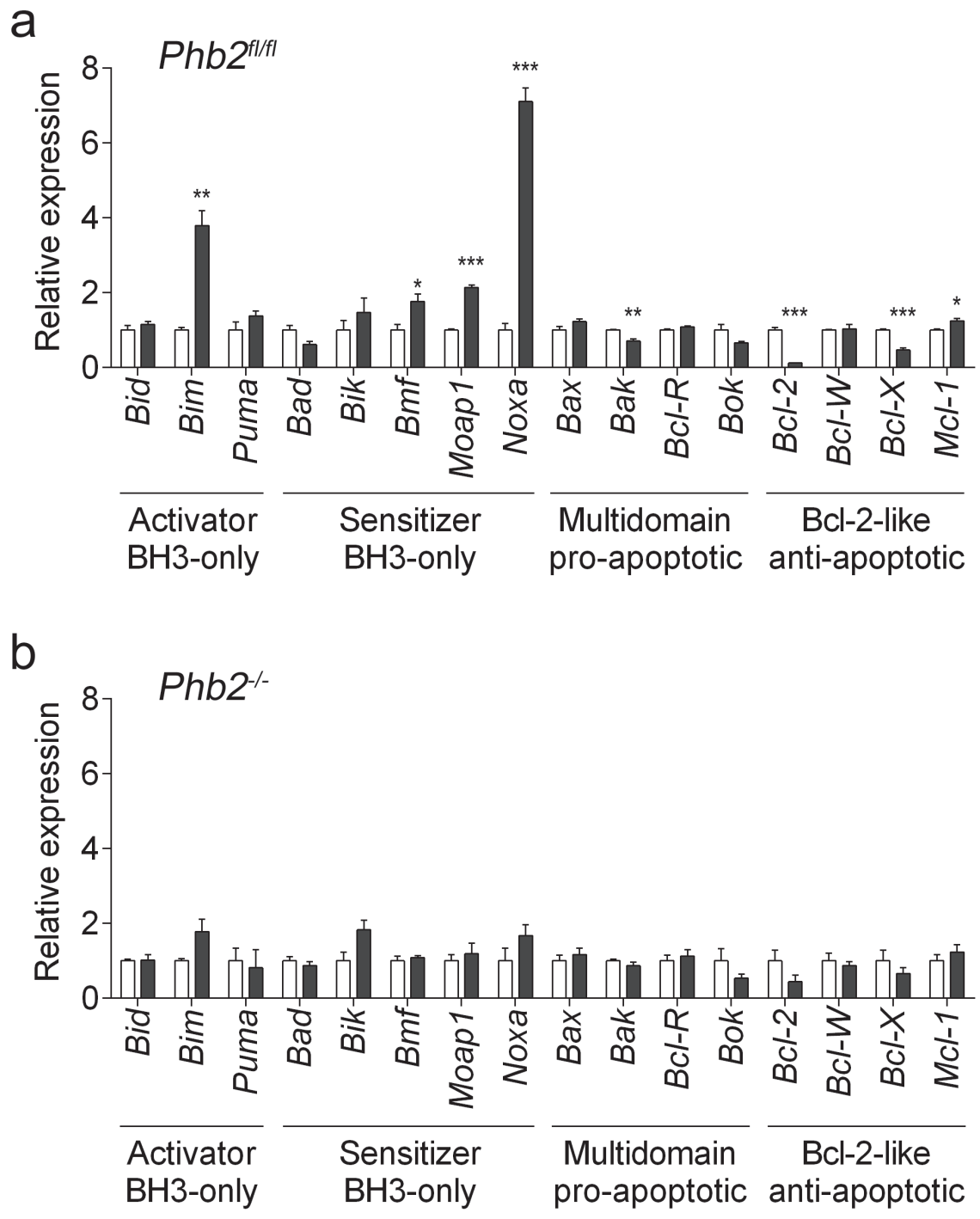

Figure 5: Fluorizoline modulates the expression of BCL-2 family members by targeting PHBs in MEFs. a. $P h b 2^{f / f l}$ MEFs were untreated (white bars) or treated with $20 \mu \mathrm{M}$ fluorizoline (black bars) for $24 \mathrm{~h}$. b. Phb $2^{f l f l}$ MEFs were transduced with Cre recombinase for $72 \mathrm{~h}\left(\mathrm{Phb2}^{--}\right)$and then untreated or treated with $20 \mu \mathrm{M}$ fluorizoline for $24 \mathrm{~h}$. a., b. mRNA levels were analyzed by RT-MLPA. White bars correspond to untreated cells, and black bars to fluorizoline-treated cells. Data show the mean values \pm SEM of three independent experiments relative to the mean of the control. ${ }^{*} p<0.05,{ }^{*} p<0.01, * * * p<0.001$ untreated versus treated cells. 
viability was still slightly decreased. Pre-treatment of $\mathrm{Bax}^{-/ /} / \mathrm{Bak}^{-/-} \mathrm{MEFs}$ with the pan-caspase inhibitor Q-VD$\mathrm{OPh}$ completely blocked fluorizoline-induced apoptosis (Supplementary Figure 6c). As the intrinsic apoptotic pathway is blocked in the absence of BAX and BAK, we assessed the role of the extrinsic apoptotic pathway by adding the caspase 8 inhibitor Z-IETD-FMK. Strikingly, inhibiting caspase 8 activity did not have any effect on fluorizoline-induced apoptosis in WT MEFs, while it could efficiently prevent the pro-apoptotic effects of fluorizoline in $\mathrm{Bax}^{-/ /} / \mathrm{Bak}^{-/}$MEFs (Supplementary Figure 6c). To corroborate these results, we used $\mathrm{Bax}^{-/ /} / \mathrm{Bak}^{-/-}$ MEFs overexpressing CrmA, a cowpox virus protein that preferentially inhibits caspase 8 [53]. Consistently, CrmA effectively inhibited apoptosis induced by fluorizoline in $\mathrm{Bax}^{-/ /} / \mathrm{Bak}^{-/}$MEFs (Supplementary Figure 6d). All together, these findings show that the mitochondrial apoptotic pathway is essential for fluorizoline-induced apoptosis. Strikingly, in the absence of BAX and BAK, fluorizoline induces a minor decrease in viability by activating caspase 8 .

\section{Prohibitins mediate the modulation of the expression of various BCL-2 family members upon fluorizoline treatment}

To gain insight into the mechanism of apoptosis induction upon fluorizoline treatment, changes in the overall apoptosis mRNA expression profile were analyzed by reverse transcriptase multiplex ligation-dependent probe amplification (RT-MLPA) in Phb2 $2^{f / f l}$ MEFs. After 24 $\mathrm{h}$ of treatment with $20 \mu \mathrm{M}$ fluorizoline, the upregulation of the pro-apoptotic genes Bim, Noxa, Bmf, and Moapl was observed, along with downregulation of the anti-apoptotic genes $\mathrm{Bcl}-2$ and $\mathrm{Bcl}-\mathrm{X}$ (Figure 5a and Supplementary Figure 7a).

Fluorizoline-induced apoptosis requires the presence of PHBs (Figure 1). It is therefore conceivable that the modulations observed in apoptosis-related gene expression do not occur in cells lacking PHBs. To test this hypothesis, we transduced $P h b 2^{f l f t}$ MEFs with Cre-recombinase for $72 \mathrm{~h}$ and then treated them with $20 \mu \mathrm{M}$ fluorizoline for 24 h. Importantly, Cre-mediated loss of PHBs abolished

b
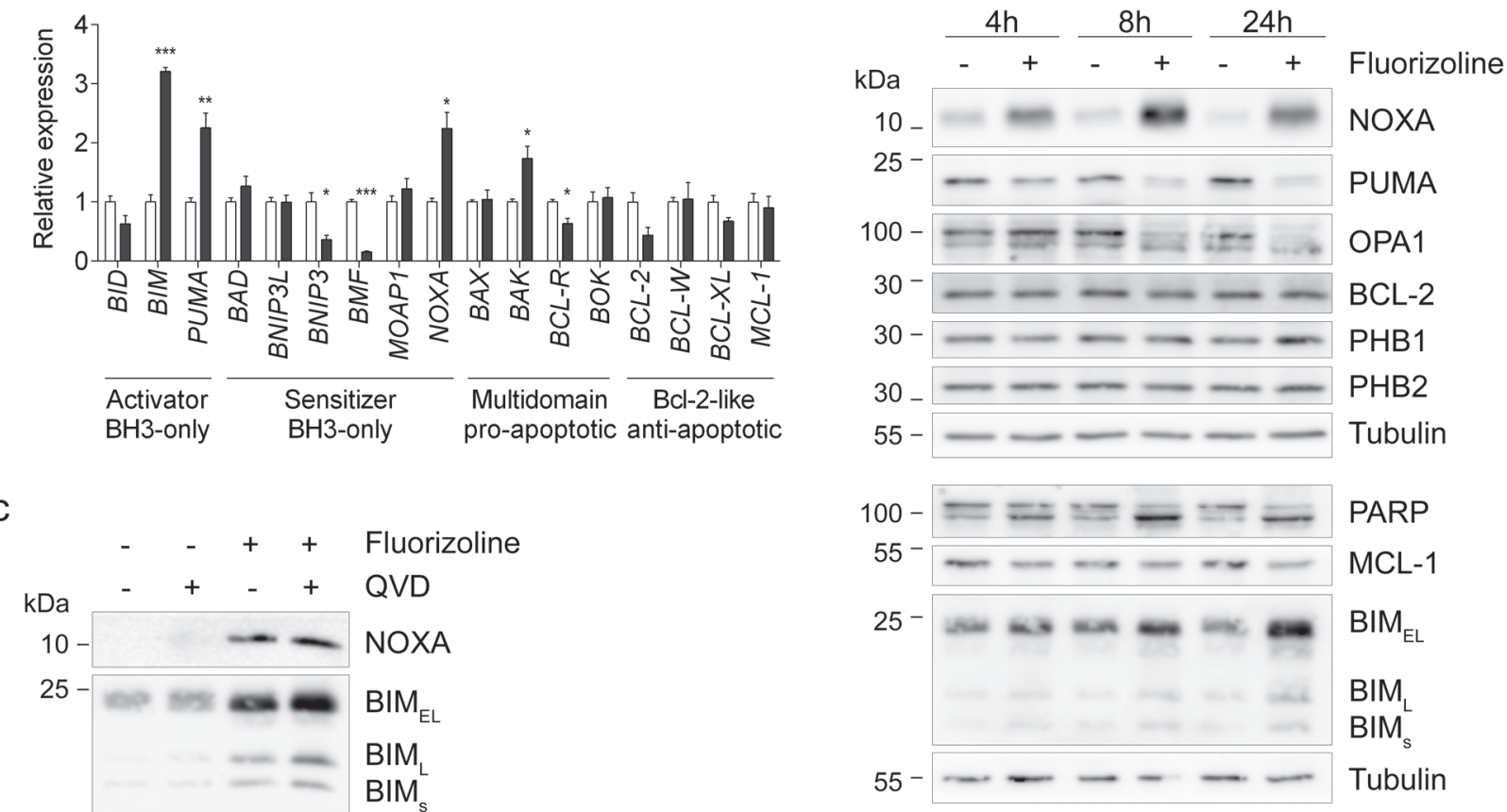

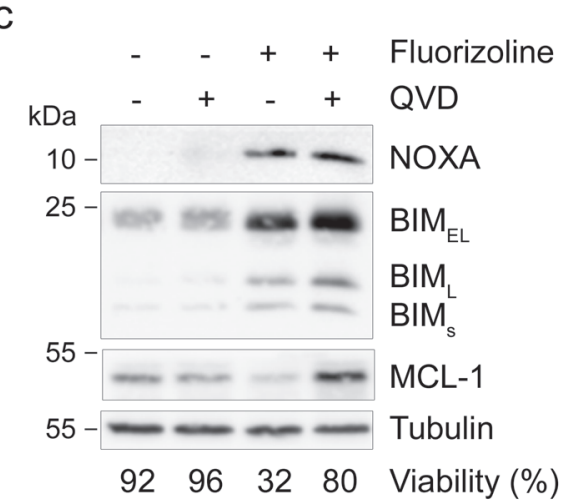

Figure 6: Fluorizoline changes mRNA and protein levels of various BCL-2 family members in HeLa cells. a. HeLa cells were untreated (white bars) or treated with $10 \mu \mathrm{M}$ fluorizoline (black bars) for $24 \mathrm{~h}$. mRNA levels were analyzed by RT-MLPA. Data show the mean values \pm SEM of three independent experiments relative to the mean of the control. ${ }^{*} p<0.05, * * p<0.01,{ }^{* * *} p<0.001$ untreated versus treated cells. b. HeLa cells were untreated or treated with $10 \mu \mathrm{M}$ fluorizoline for 4,8 and $24 \mathrm{~h}$. c. HeLa cells were pre-incubated with $20 \mu \mathrm{M}$ caspase inhibitor Q-VD-OPh for $30 \mathrm{~min}$ and then treated with $10 \mu \mathrm{M}$ fluorizoline for $24 \mathrm{~h}$. b., c. Protein levels were analyzed by western blot. Tubulin was used as a loading control. These are representative images of at least three independent experiments. 
the modulations of mRNA levels triggered by fluorizoline (Figure 5b and Supplementary Figure 7b). Thus, the presence of PHBs is required for fluorizoline-induced changes in the apoptosis-related mRNA expression profile.

Interestingly, treatment with fluorizoline increased BIM protein levels in $P h b 2^{f / f l}$ MEFs, although these levels were not modulated in $P h b 2^{-/}$MEFs (Supplementary Figure 8). NOXA protein levels could not be analyzed due to lack of proper antibodies with the capacity to detect the mouse protein (data not shown). Consequently, we further
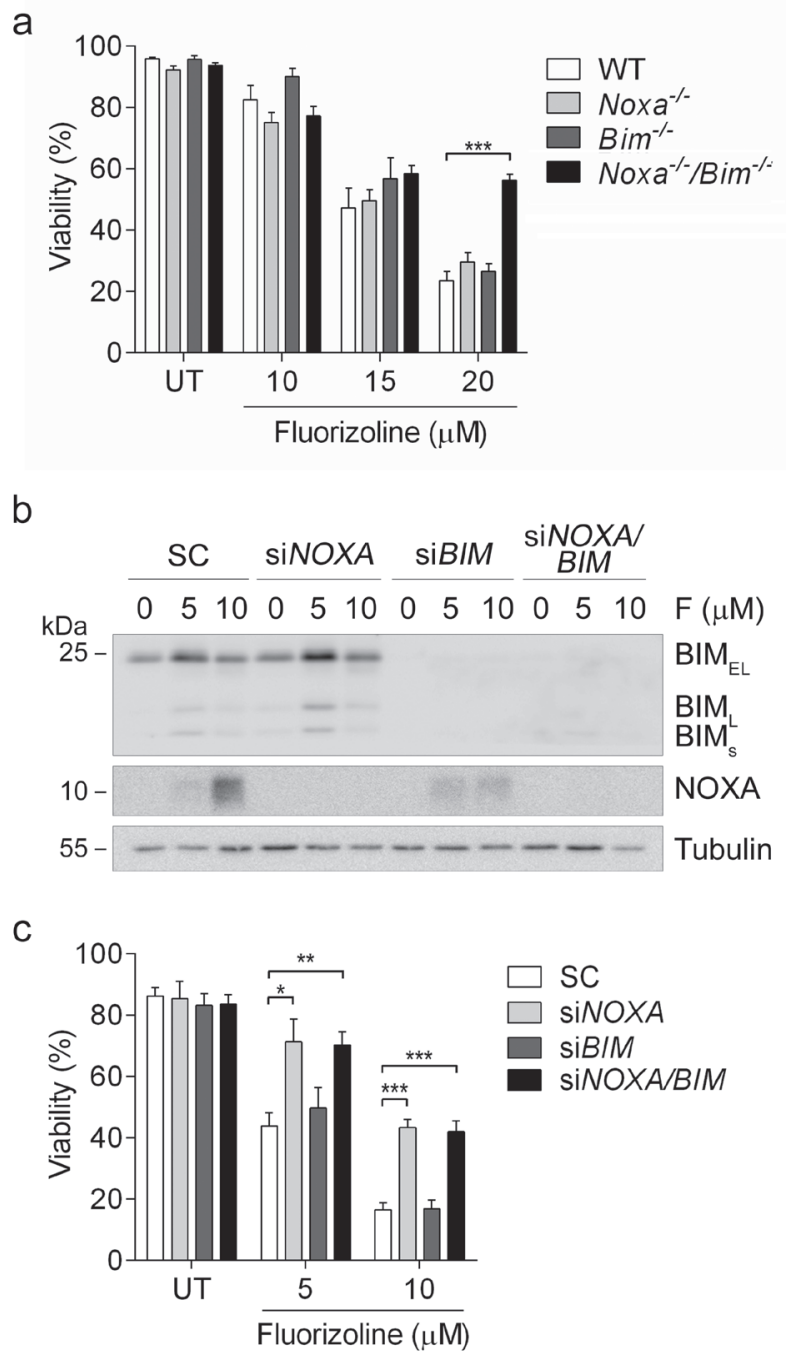

Figure 7: Loss of NOXA and BIM blocks fluorizoline-induced apoptosis. a. WT, $\mathrm{Noxa}^{-/}, \mathrm{Bim}^{-/-}$or $\mathrm{Noxa}^{-/ /} \mathrm{Bim}^{-/}$MEFs were untreated (UT) or treated with 10,15 or $20 \mu \mathrm{M}$ of fluorizoline for $24 \mathrm{~h}$. b., c. HeLa cells were transfected with scramble (SC), NOXA siRNA ( $\operatorname{si} O X A), B I M$ siRNA (siBIM), or both NOXA and BIM siRNA (siNOXA/BIM) for $48 \mathrm{~h}$ and then untreated (UT) or treated with 5 or $10 \mu \mathrm{M}$ fluorizoline (F) for $24 \mathrm{~h}$. b. Protein levels were analyzed by western blot. Tubulin was used as a loading control. This is a representative image of at least three independent experiments. a., c. Viability was measured by flow cytometry and it is expressed as the mean $\pm \operatorname{SEM}(n \geq 3)$ of the percentage of non-apoptotic cells (annexin V-negative). ${ }^{*} p<0.05,{ }^{* *} p<0.01, * * * p<0.001$. studied fluorizoline-induced apoptosis by analyzing changes in the expression of BCL-2 family members in HeLa cells, as there are more antibodies available for the detection of human BCL-2 family proteins.

First, the apoptosis-related gene expression profile was examined by RT-MLPA in HeLa cells. Treatment with $10 \mu \mathrm{M}$ fluorizoline increased the pro-apoptotic $B I M$, $P U M A, N O X A$, and $B A K \mathrm{mRNA}$ levels (Figure 6a and Supplementary Figure 9). Next, we sought to examine whether these modulations of the mRNA levels resulted in changes in the corresponding protein levels. We observed a time-dependent upregulation of NOXA and BIM, as well as decreases in PUMA and MCL-1 protein levels (Figure 6b). Despite the decreases in $B C L-2$ mRNA levels, fluorizoline did not significantly modulate its protein levels, a finding consistent with the long half-life of this protein [54]. In addition, PHB protein levels were not modified upon fluorizoline treatment. Interestingly, increases in NOXA and BIM preceded caspase activation, as pre-incubation with pan-caspase inhibitor Q-VD-OPh did not block their upregulation (Figure 6c). In contrast, caspase inhibition abolished the decrease in MCL-1 mediated by fluorizoline treatment, thereby demonstrating that it is a caspase-dependent event. Thus, PHBs mediate fluorizoline-induced changes in Noxa and Bim expression, the protein levels of which increased prior to caspase activation. These modulations could explain the apoptotic outcome observed.

To validate the increases in BIM and NOXA protein levels, we analyzed the effects of fluorizoline in primary cancer cells. Specifically, we used cells from four patients with different hematological malignancies, namely chronic myeloid leukemia-derived blast crisis, mantle cell lymphoma, B cell chronic lymphoproliferative syndrome and adult T-cell leukemia/lymphoma. Interestingly, treatment with fluorizoline resulted in a decrease in viability and an increase in NOXA protein levels, whereas BIM protein levels were not modified (Supplementary Figure 10a-d). We also analyzed changes in BCL-2 family members following fluorizoline treatment in various cancer cell lines. NOXA and BIM protein levels increased in a dose-dependent manner in HT-29, a colon cancer cell line, as well as in A375P and WM1552, two melanoma cell lines (Supplementary Figure 10e-f). In Jurkat cells, we only observed fluorizoline-induced increases in NOXA protein levels (Supplementary Figure 10g). Hence, fluorizoline seems to mainly increase NOXA protein levels, while BIM is also upregulated in some cancer cells.

\section{Role of NOXA and BIM in fluorizoline-induced apoptosis}

We sought to further study the role of NOXA and BIM in fluorizoline-induced apoptosis. To this end, we performed a viability assay in MEFs lacking Noxa, 
Bim, or both. Noxa ${ }^{-/ /} \mathrm{Bim}^{-/}$MEFs were resistant to the pro-apoptotic effects of fluorizoline, whereas WT, $\mathrm{Noxa}^{-/-}$and $\mathrm{Bim}^{-/}$MEFs showed a similar sensitivity to this compound (Figure 7a). In addition, NOXA and BIM were downregulated by siRNA transfection in HeLa cells and their response to fluorizoline treatment was assessed. Cells lacking BIM were sensitive to the pro-apoptotic effects of fluorizoline, while lack of NOXA conferred resistance to these effects. Simultaneous depletion of NOXA and BIM did not increase resistance to this compound when compared to depletion of NOXA alone (Figure 7b-7c).

All together, these data demonstrate that fluorizoline induces the mitochondrial apoptotic pathway predominantly through the upregulation of NOXA and, depending on the cell type, also of BIM.

\section{DISCUSSION}

In the present study we describe the mechanism of apoptosis induction exerted by fluorizoline, a new proapoptotic agent with a fluorinated thiazoline scaffold. It was previously described that fluorizoline directly binds to PHB1 and PHB2 [2]. Here we show that PHBs mediate the pro-apoptotic effects of fluorizoline through two approaches. Depletion of Phb2 either by Cre-mediated recombination in $P h b 2^{f / f l}$ MEFs or by siRNA transfection in MEFs conferred resistance to fluorizoline. Hence, fluorizoline is a new synthetic agent that reduces cell viability by specifically targeting PHBs.

PHBs play a key role in the maintenance of mitochondrial homeostasis. High expression of PHBs has been found in cells that heavily depend on mitochondrial function, notably proliferating cells. It is conceivable that these cells are particularly susceptible to the lack of functional PHBs [4]. In fact, downregulation of PHBs in various cell lines blocks cell proliferation [10, 22, 35] and also induces apoptosis $[13,55,56]$. Overexpression of PHBs protects cells from apoptosis induced by various stimuli, an observation that is consistent with PHB1 having a cytoprotective role [11]. In MEFs, PHBs exert their anti-apoptotic function via L-OPA1, as the increased sensitivity to apoptosis observed in the absence of PHBs can be counteracted by re-expression of a non-cleavable variant of L-OPA1 [10]. In addition, it has been reported that PHB overexpression inhibits apoptosis through the induction of $\mathrm{BCL}-2$ and $\mathrm{BCL}-\mathrm{X}_{\mathrm{L}}$ [23] and that downregulation of PHBs reduces BCL-X $\mathrm{L}_{\mathrm{L}}$ levels [57]. Interestingly, overexpression of $\mathrm{BCL}-\mathrm{X}_{\mathrm{L}}$ protected cells from fluorizoline-induced apoptosis.

The role of PHBs in cancer has been largely discussed. Although some reports point to an antitumorigenic role of PHBs, a growing body of evidence links these proteins to tumor development [11, 21, 29, $34,35]$. Fluorizoline has the capacity to induce apoptosis in a wide range of cancer cell lines, including glioma and prostate cancer cell lines [2], in which PHBs were reported to have an anti-tumorigenic role $[31,32]$. Thus, the induction of apoptosis by targeting PHBs emerges as a new therapy for cancer.

The exact mechanism by which fluorizoline induces apoptosis remains to be elucidated. The loss of either PHB1 or PHB2 may destabilize mitochondrial PHBs complexes, leading to the activation of quality control mechanisms, which would in turn degrade the other partner $[6,58]$. Therefore, the observation that PHB protein levels are maintained upon fluorizoline treatment suggests that the PHBs ring-like complex in the IMM is not destabilized. Treatment with fluorizoline increased the production of ROS, as observed in the absence of PHBs in various cell types [16-19, 24, 59, 60]. However, we proved that the generation of ROS was independent of PHBs and apoptosis induction, discarding oxidative stress as a mechanism of action of fluorizoline. PHBs are known to physically interact with several subunits of complex I and II of the respiratory chain, presumably contributing to their proper assembly and stability [61-63]. In fact, deletion of PHBs decreases the activity of various complexes of the respiratory chain $[16,26,59]$. We cannot exclude that fluorizoline will affect the activity of these complexes due to its PHBs-binding properties.

Treatment with fluorizoline induces fragmentation of the mitochondrial network, cristae remodeling and loss of L-OPA1, which is consistent with the role of this protein in mitochondrial fusion and in the maintenance of cristae structure [14, 15]. Strikingly, PHB-depleted cells also present fragmented mitochondrial network and aberrant cristae morphogenesis, which are attributed to the loss of L-OPA1 [10]. However, it is worth mentioning that this observation cannot be exclusively interpreted as a proof that fluorizoline targets PHBs. Other apoptotic stimuli have been reported to trigger the same changes in mitochondrial structure [38-41] and the processing of L-OPA1 [42, 64, 65], which allows reorganization of mitochondrial cristae and facilitates cytochrome $c$ release $[66,67]$. Our results demonstrate that fluorizoline was able to induce apoptosis independently of the loss of L-OPA1 forms, which excludes this event as the cause of apoptosis induction.

We have shown that fluorizoline triggers the intrinsic apoptotic pathway, as BAX and BAK are required for fluorizoline-induced apoptosis. The protection observed in $B a k^{/-}$MEFs could be related to the recently reported requirement of $\mathrm{BAK}$ for efficient $\mathrm{BAX}$ translocation and oligomerization at the outer mitochondrial membrane [68]. The activation of the intrinsic apoptotic pathway involving BCL-2 family members appears to be necessary for the successful outcome of many cancer treatments [48]. Expression analysis revealed a consistent upregulation of two BH3-only proteins, namely the activator Bim and the sensitizer Noxa in MEF and HeLa cells upon fluorizoline treatment. Of note, these modulations were dependent on the presence of PHBs in MEFs. 
Importantly, fluorizoline induced increases in NOXA and BIM protein levels prior to caspase activation, which could explain the apoptotic outcome. NOXA and BIM are essential for the induction of apoptosis in response to a variety of pro-apoptotic insults [48, 69-71]. The lack of NOXA in HeLa cells conferred resistance to the pro-apoptotic effects of fluorizoline, although this was not observed in $\mathrm{Noxa}^{-/-}$MEFs. These observations are consistent with the reported differences in the apoptotic potential of NOXA in function of the cell type [70]. Specifically, NOXA overexpression induces significant apoptosis in HeLa cells [72], while in MEFs it is poorly apoptotic [73, 74]. In MEFs, lack of NOXA and BIM conferred significant resistance to fluorizoline-induced apoptosis, thus revealing a key role for these BH3-only proteins in the mechanism of action of fluorizoline. On the other hand, downregulation of both NOXA and BIM in HeLa cells failed to offer more protection than the absence of NOXA alone, thereby suggesting that BIM plays only a minor role in these cells. The consistent upregulation of NOXA protein levels in all the cancer cell types that were analyzed points towards a main function of this $\mathrm{BH} 3-$ only protein in fluorizoline-induced apoptosis. Compared to PHB-depleted cells, the loss of the crucial BH3-only proteins (i.e. NOXA and BIM for MEFs and NOXA for HeLa cells) blocked fluorizoline-induced apoptosis less efficiently, thus suggesting a contribution of other BCL-2 family members modulated in a PHB-dependent manner.

In addition to their role in mitochondria, PHBs also localize in other cellular compartments, including the nucleus and the plasma membrane, in a wide range of cell types $[11,75]$. In the plasma membrane, PHBs have been involved in the activation of the signaling pathways Ras-Raf-MAPK and the tyrosine kinase Syk [76-79]. In the nucleus, PHBs were reported to regulate the activity of various transcription factors such as p53, E2F1, and estrogen receptor [11]. Whether the fluorizoline-induced transcriptional modulations are directly mediated by nuclear PHBs or indirectly mediated by PHBs in other cellular compartments requires further analysis.

Similar to fluorizoline, the effects of three natural products that bind to PHBs have been reported. First, capsaicin binds to $\mathrm{PHB} 2$ to induce cytochrome $c$ release from mitochondria [80]. Second, the depsipeptide aurilide was shown to selectively bind to PHB1 in the mitochondria, leading to rapid mitochondrial fragmentation and the induction of apoptosis [81]. Third, Rocaglamide A, a member of the flavagline class of compounds, binds to both PHB1 and PHB2 at the cell membrane to inhibit Raf activation and Raf-MEK-ERKmediated cell cycle progression and cell proliferation in tumor cell lines, without inducing mitochondrial fragmentation [82]. Interestingly, Rocaglamide $\mathrm{A}$ and other related flavaglines have pro-apoptotic activities both in vitro and in vivo in various cancer cells; however, it remains unknown whether PHBs are involved in their mechanism of apoptosis induction [11, 83]. The complexity of the synthesis or the restricted availability of these compounds may hinder their use in therapeutics. In contrast, fluorizoline synthesis is practical, versatile, short, and reproducible, and thus amenable to gram-scale batches [2]. In vivo, sub-acute toxicity studies in mice revealed that fluorizoline only produces some liver toxicity at the higher doses that were tested (data not shown). Thus, it would be possible to analyze its anti-tumor effects in vivo.

In conclusion, this study demonstrates that PHBs are required for fluorizoline-induced apoptosis. PHBs mediate the upregulation of NOXA and BIM, which are crucial for the pro-apoptotic effects of fluorizoline. Moreover, our findings reveal that PHBs are amenable to modulation by small molecules to finally induce apoptosis, and thus further contributes to highlighting the suitability of PHBs as promising therapeutic targets.

\section{MATERIALS AND METHODS}

\section{Reagents}

The synthesis of racemic fluorizoline was performed as previously described [2]. Actinomycin D was purchased from Enzo Life Sciences (Farmingdale, New York, USA). Q-VD-OPh and Z-IETD-FMK were from R\&D systems (Minneapolis, Minnesota, USA). Recombinant mouse TNF $\alpha$ was from PeproTech (Rocky Hill, New Jersey, USA). MnTBAP, etoposide and cycloheximide were from Sigma-Aldrich (Saint Louis, Missouri, USA).

\section{Cell lines culture}

WT and $P h b 2^{f / f l}$ MEFs were generated as previously described [10]. $P h b 2^{f / /}$ MEFs were generated by transducing $P h b 2^{f / f t}$ MEFs with Cre recombinase for $72 \mathrm{~h}$. Cells were sorted individually in a 96-well plate and then allowed to grow for several days. Genotyping was performed by PCR analysis as previously described [10]. MEFs WT, Bax ${ }^{-/}, \mathrm{Bak}^{/-}$and $\mathrm{Bax}^{-/ /} / \mathrm{Bak}^{/-}$MEFs were obtained from Dr. Korsmeyer's laboratory [50]. HeLa and Jurkat cells were supplied by the European Collection of Cell Culture. Oma1 $1^{-/}$MEFs were a kind gift of Dr. LopezOtín (Instituto Universitario de Oncología, Universidad de Oviedo, Spain). WT, Bim ${ }^{-/}$, Noxa ${ }^{-/}$and $\mathrm{Bim}^{-/ /} / \mathrm{Noxa}^{-/-} \mathrm{MEFs}$ were kindly provided by Dr. Andreas Villunger (Medical University of Innsbruck, Austria). Jurkat-BCL-X $\mathrm{L}_{\mathrm{L}}$ cells were generated by Dr. Victor Yuste (Universitat Autònoma de Barcelona, Spain). Bax $x^{-/} / B a k^{-/}$MEFs overexpressing CrmA were kindly provided by Dr. Muñoz-Pinedo [84]. HT29 and MW1552 cells were supplied by ATCC. A375P cells were provided by Dr. I. J. Fidler (MD Anderson Cancer Center, Houston, USA).

All cell lines were cultured in Dulbecco's Modified 
Eagle Medium except for Jurkat, which were cultured in Roswell Park Memorial Institute (RPMI) 1640 Medium supplemented with $10 \%$ fetal bovine serum, 2 $\mathrm{mM}$ L-glutamine, $100 \mathrm{U} / \mathrm{mL}$ penicillin, and $100 \mathrm{ng} / \mathrm{mL}$ streptomycin (all from Biological Industries, Israel) at $37^{\circ} \mathrm{C}$ in a humidified atmosphere containing $5 \%$ carbon dioxide.

\section{Primary samples and cell isolation}

Peripheral blood samples and bone marrow aspirates from untreated patients were obtained after informed consent in accordance with protocols approved by the Human Research Ethics Committees of the Hospital ICO-Duran i Reynals, L'Hospitalet de Llobregat, Spain. Patients with chronic myeloid leukemia-derived blast crisis, mantle cell lymphoma, B cell chronic lymphoproliferative syndrome and adult T-cell leukemia/ lymphoma were diagnosed according to standard clinical and laboratory criteria. Peripheral blood and bone marrow mononuclear cells were isolated by centrifugation on a Biocoll (Biochrom AG, Berlin, Germany) gradient and cryopreserved in liquid nitrogen in the presence of $10 \%$ DMSO (Sigma-Aldrich). Mononuclear cells were cultured immediately after thawing or isolation at a concentration of $1 \times 10^{6}$ cells $/ \mathrm{mL}$ in RPMI 1640 culture medium supplemented with $10 \%$ heat-inactivated fetal bovine serum, $2 \mathrm{mM}$ L-glutamine, $100 \mathrm{U} / \mathrm{mL}$ penicillin, and 100 $\mu \mathrm{g} / \mathrm{mL}$ streptomycin (all from Biological Industries) at $37^{\circ} \mathrm{C}$ in a humidified atmosphere containing $5 \%$ carbon dioxide.

\section{Transduction of MEFs with Cre-recombinase}

Recombinant His-TAT-NLS-Cre-recombinase (HTNC) was expressed and purified as previously described [85]. $6 \mu \mathrm{M}$ HTNC was diluted in DMEM/PBS $(1: 1)$, sterile filtered and applied to WT and $P h b 2^{f / f l}$ MEFs for $20 \mathrm{~h}$. Afterwards, cells were washed with PBS and grown in complete medium for $48 \mathrm{~h}$. MEFs were then treated with fluorizoline for $24 \mathrm{~h}$.

\section{Analysis of cell viability by flow cytometry}

Cell viability was measured by exposure of phosphatidylserine and expressed as the percentage of annexin V-APC-negative population. Cells were washed and incubated with annexin binding buffer and annexin V-APC for $15 \mathrm{~min}$ in the dark and then analyzed by flow cytometry using FACSCalibur and CellQuest-Pro software (BD Biosciences, Franklin Lakes, New Jersey, USA).

\section{Western blot}

Whole cell protein extracts were obtained by lysing cells with Laemmli sample buffer or RIPA buffer (Supplementary Figure 1b). Protein concentration was measured with the Micro BCA Protein Assay Reagent kit (Pierce, Rockford, Illinois, USA). 20-50 $\mu \mathrm{g}$ of protein extracts were subjected to reducing conditions, loaded onto a polyacrylamide gel and then transferred to Immobilon-P membranes from Millipore (Billerica, Massachusetts, USA) or Protran 0.2 nitrocellulose membranes from Amersham (Buckinghamshire, UK) (Supplementary Figure 1b). One hour after blocking with $5 \%(\mathrm{w} / \mathrm{v})$ non-fat milk in Tris-buffered saline with Tween ${ }^{\circledR} 20$, membranes were incubated with the following specific primary antibodies: cleaved caspase 3 (9661, Cell Signalling, Danvers, Massachusetts, USA); PARP (9542, Cell Signalling); OPA1 (612607, BD Biosciences); PHB1 (H-80, Santa Cruz, Dallas, Texas, USA); PHB2 (07-234, Millipore); Tubulin (CP06, Millipore); $\beta$-Actin (A5441, Sigma-Aldrich); ERK2 (clone 1B3B9, 05-157, Millipore); BAX (AB2915, Millipore); BAK (06-536, Millipore); BCL-X $_{\mathrm{L}}$ (B22630, Transduction Laboratories); MCL-1 (S-19, sc-819, Santa Cruz); BIM (2933, Cell Signaling); NOXA (ab13654, Abcam, Cambridge, UK); PUMA (4976, Cell Signaling); and BCL-2 (M0887, Dako, Santa Clara, California, USA). For Supplementary Figure $1 \mathrm{~b}$, we used different antibodies for PHB1 (603102, BioLegend, San Diego, California) and PHB2 (611802, BioLegend). Antibody binding was detected using a secondary antibody conjugated to horseradish peroxidase, and the enhanced chemiluminescence detection system (Amersham). Molecular size markers (\#26619, Thermo Fisher Scientific) are indicated in $\mathrm{kDa}$ in each figure.

\section{Transient transfection}

siRNA transfection. MEFs were transfected with scramble (12935-300) or Phb2 siRNA (MSS236022), while HeLa cells were transfected with scramble (12935300), BAK (HSS141354, HSS141355, HSS141356), $B A X$ (HSS184085, HSS184086, HSS184087), NOXA (HSS143341, HSS143342, HSS143343), or BIM (s195011) siRNA using the Lipofectamine ${ }^{\circledR}$ RNAiMax Reagent (all from Thermo Fisher Scientific, Waltham, Massachussets, USA). Complexes were added directly to growing cells in DMEM and incubated for $24 \mathrm{~h}$, followed by washing with PBS buffer and addition of fresh DMEM. MEFs were used in experiments $72 \mathrm{~h}$ after siRNA transfection, and HeLa cells were used after 48 $\mathrm{h}$. The efficiency of the downregulation was assessed by western blot. Plasmid transfection. HeLa cells were transfected with either pcDNA3.1, OPA1- $\Delta$ S1 construct (kindly provided by Dr. Ishihara, Kurume University, Japan) or 3X-FLAG PHB1 and PHB2 plasmids (a kind 
gift of Dr. Handa, Tokyo Institute of Technology, Japan) using the Lipofectamine ${ }^{\circledR}$ LTX Reagent (Thermo Fisher Scientific). Cells were used in experiments $48 \mathrm{~h}$ after transfection. MEFs were transfected with PHB1 and PHB2 overexpression plasmids using the Lipofectamine ${ }^{\circledR}$ 2000 Reagent (Thermo Fisher Scientific). Complexes were incubated for $25 \mathrm{~min}$ at room temperature and added dropwise to growing cells in DMEM. Cells were used in experiments $16 \mathrm{~h}$ after transfection. The efficiency of the overexpression was assessed by western blot.

\section{Fluorescence imaging}

HeLa cells were grown on sterilized poly-L-lysinecoated coverslips $(0.01 \%$ solution, Sigma-Aldrich) and incubated with $100 \mathrm{nM}$ MitoTracker ${ }^{\circledR}$ Red CMXRos (Thermo Fisher Scientific) for $30 \mathrm{~min}$ at $37^{\circ} \mathrm{C}$. Cells were visualized using spectral confocal microscope (TCS-SL, Leica Microsystems, Wetzlar, Germany) and a Plan-Apochromat $63 \times / 1.4$ N.A. immersion oil objective (Leica Microsystems). Images were acquired using the accompanying image processing software from Cytovision.

\section{Transmission electron microscopy}

HeLa cells were rinsed with PBS and immediately fixed by immersion in $0.1 \mathrm{M}$ glutaraldehyde in phosphate buffer for $2-3 \mathrm{~h}$ at $4^{\circ} \mathrm{C}$. Cells were gently scraped, collected, and pelleted by centrifugation. Cells were treated with $1 \%$ osmium tetroxide and after dehydration were embedded in epoxy resin (Araldite, Basel, Switzerland). Thin sections were cut with a diamond knife on a ultramicrotome (Ultracut, Reichert-Jung, Depew, New York, USA), stained with uranyl actetate/lead citrate and each sample was placed into grids to be examined in a JEOL 1010 electron microscope equipped with a Bioscan digital camera (Gatan, Pleasanton, California, USA).

\section{ROS production}

Superoxide anion and hydroxyl radical production was analyzed by incubating Jurkat or MEF cells with $2.5 \mu \mathrm{M}$ CellROX ${ }^{\circledR}$ Deep Red Reagent (Thermo Fisher Scientific) during the last $30 \mathrm{~min}$ of the treatment at $37^{\circ} \mathrm{C}$. ROS production was measured by flow cytometry using FACSCalibur and CellQuest-Pro software (BD Biosciences), and expressed as the mean fluorescence intensity relative to the mean of the control.

\section{Measurement of mitochondrial membrane potential}

Jurkat cells were stained with $100 \mathrm{nM}$ MitoTracker ${ }^{\circledR}$ Red CMXRos (Thermo Fisher Scientific) during the last $30 \mathrm{~min}$ of the treatment at $37^{\circ} \mathrm{C}$ and then analyzed by flow cytometry using MoFlo ${ }^{\circledR}$ Astrios (Beckman Coulter, Brea, California, USA). Decreased fluorescence indicates a loss of $\Delta \Psi \mathrm{m}$.

\section{Reverse transcriptase multiplex ligation- dependent probe amplification (RT-MLPA)}

RNA content was analyzed by RT-MLPA using the SALSA MLPA KIT RM002-B1 (MEFs) and R011-C1 (HeLa cells) Apoptosis mRNA from MRC-Holland (Amsterdam, The Netherlands) for the simultaneous detection of 40 mRNA molecules [86]. In brief, $200 \mathrm{ng}$ total RNA were first reverse transcribed using a gene specific primer mix. The resulting cDNA was annealed overnight at $60^{\circ} \mathrm{C}$ to the RT-MLPA probe mix. Annealed oligonucleotides were ligated by adding Ligase-65 (MRCHolland) and incubated at $54^{\circ} \mathrm{C}$ for $15 \mathrm{~min}$. Ligation products were amplified by PCR $\left(35\right.$ cycles, $30 \mathrm{~s}$ at $95^{\circ} \mathrm{C}$; $30 \mathrm{~s}$ at $60^{\circ} \mathrm{C}$, and $1 \mathrm{~min}$ at $72^{\circ} \mathrm{C}$ ) with one unlabeled and one FAM-labeled primer. PCR fragments were separated by capillary electrophoresis on a 48-capillary ABI-Prism 3730 Genetic Analyzer (Applied Biosystems, California, USA). Peak area and height were measured using GeneMapper v3.0 analysis software (Applied Biosystems). Individual peaks were calculated relative to the sum of all peak data to normalize for fluctuations in total signals between samples. Data are shown as the mean \pm SEM relative to the mean of the controls.

\section{Statistical analysis}

The results are shown as the mean \pm standard error of the mean (SEM) of values obtained in three or more independent experiments. Statistical analysis was performed using the Student's $t$ test (two-tailed) by using GraphPad Prism 6.0c Software Inc. $p$ values below 0.05 were considered statistically significant $\left({ }^{*} p<0.05 ; * *^{*} p<\right.$ $0.01 ; * * * p<0.001)$.

\section{ACKNOWLEDGMENTS}

We thank the Scientific and Technological Centers of the Bellvitge Campus at the University of Barcelona and the Cytometry Facility at the University of Cologne for their technical support, Dr. Santiago Ambrosio and Dr. Isabel Fabregat for helpful discussions, Gemma Garcia Vicién for lab assistance and Tanya Yates for English corrections. We also thank Dr. López-Otín, Dr. Villunger, 
Dr. Muñoz-Pinedo, Dr. Yuste, Dr. Marzo, Dr. Fabra and the late Dr. Korsmeyer for kindly providing cells; Dr. Handa for providing 3XFLAG-PHBs plasmids and Dr. Ishihara for providing OPA1- $\Delta \mathrm{S} 1$ plasmid.

\section{FUNDING}

This study was supported by grants from the Ministerio de Economía y Competitividad (SAF201341611-R), Red Temática de Investigación Cooperativa en Cáncer (RTICC) (RD12/0036/0029), Instituto de Salud Carlos III, European Regional Development Fund (ERDF), Fundació Bosch i Gimpera (AVCRI-PPV022-08Banco Santander), Consejo Interinstitucional de Ciencia y Tecnología (CICYT) (CTQ2012-30930) and AGAURGeneralitat de Catalunya (2014SGR935, 2014SGR137). Work in the laboratory of T.L. was supported by a grant from the European Research Council (AdG No. 233078). C.M-M. and J.S-E. are recipients of a research fellowship from the Ministerio de Economía y Competitividad.

\section{CONFLICTS OF INTEREST}

A.P-P., D.M.G-G., S.P., F.A., R.L., D.I-S., and J.G. patented the use of fluorinated thiazolines in the treatment of cancer. The remaining authors declare no conflict of interest.

\section{REFERENCES}

1. Hanahan D, Weinberg RA. Hallmarks of cancer: the next generation. Cell. 2011; 144:646-74.

2. Pérez-Perarnau A, Preciado S, Palmeri CM, MoncunillMassaguer C, Iglesias-Serret D, González-Gironès DM, Miguel M, Karasawa S, Sakamoto S, Cosialls AM, RubioPatiño C, Saura-Esteller J, Ramón R, Caja L, Fabregat I, et al. A Trifluorinated Thiazoline Scaffold Leading to Proapoptotic Agents Targeting Prohibitins. Angew Chemie Int Ed. 2014; 53:10150-4.

3. Vousden KH, Lane DP. p53 in health and disease. Nat Rev Mol Cell Biol. 2007; 8:275-83.

4. Artal-Sanz M, Tavernarakis N. Prohibitin and mitochondrial biology. Trends Endocrinol Metab. 2009; 20:394-401.

5. Artal-Sanz M, Tavernarakis N. Prohibitin couples diapause signalling to mitochondrial metabolism during ageing in $\mathrm{C}$. elegans. Nature. 2009; 461:793-7.

6. Osman C, Merkwirth C, Langer T. Prohibitins and the functional compartmentalization of mitochondrial membranes. J Cell Sci. 2009; 122:3823-30.

7. Artal-Sanz M, Tsang WY, Willems EM, Grivell LA, Lemire BD, van der Spek H, Nijtmans LGJ, Sanz MA. The mitochondrial prohibitin complex is essential for embryonic viability and germline function in Caenorhabditis elegans. J Biol Chem. 2003; 278:32091-9.
8. Park S-E, Xu J, Frolova A, Liao L, O’Malley BW, Katzenellenbogen BS. Genetic deletion of the repressor of estrogen receptor activity (REA) enhances the response to estrogen in target tissues in vivo. Mol Cell Biol. 2005; 25:1989-99.

9. He B, Feng Q, Mukherjee A, Lonard DM, DeMayo FJ, Katzenellenbogen BS, Lydon JP, O’Malley BW. A repressive role for prohibitin in estrogen signaling. Mol Endocrinol. 2008; 22:344-60.

10. Merkwirth C, Dargazanli S, Tatsuta T, Geimer S, Löwer B, Wunderlich FT, von Kleist-Retzow J-C, Waisman A, Westermann B, Langer T. Prohibitins control cell proliferation and apoptosis by regulating OPA1-dependent cristae morphogenesis in mitochondria. Genes Dev. 2008; 22:476-88.

11. Thuaud F, Ribeiro N, Nebigil CG, Désaubry L. Prohibitin ligands in cell death and survival: mode of action and therapeutic potential. Chem Biol. 2013; 20:316-31.

12. Merkwirth $\mathrm{C}$, Langer $\mathrm{T}$. Prohibitin function within mitochondria: essential roles for cell proliferation and cristae morphogenesis. Biochim Biophys Acta. 2009; 1793:27-32.

13. Kasashima K, Ohta E, Kagawa Y, Endo H. Mitochondrial functions and estrogen receptor-dependent nuclear translocation of pleiotropic human prohibitin 2. J Biol Chem. 2006; 281:36401-10.

14. Olichon A, Baricault L, Gas N, Guillou E, Valette A, Belenguer P, Lenaers G. Loss of OPA1 perturbates the mitochondrial inner membrane structure and integrity, leading to cytochrome c release and apoptosis. J Biol Chem. 2003; 278:7743-6.

15. Arnoult D, Grodet A, Lee Y-J, Estaquier J, Blackstone C. Release of OPA1 during apoptosis participates in the rapid and complete release of cytochrome $\mathrm{c}$ and subsequent mitochondrial fragmentation. J Biol Chem. 2005; 280:35742-50.

16. Schleicher M, Shepherd BR, Suarez Y, FernandezHernando C, Yu J, Pan Y, Acevedo LM, Shadel GS, Sessa WC. Prohibitin-1 maintains the angiogenic capacity of endothelial cells by regulating mitochondrial function and senescence. J Cell Biol. 2008; 180:101-12.

17. Ko KS, Tomasi ML, Iglesias-Ara A, French BA, French SW, Ramani K, Lozano JJ, Oh P, He L, Stiles BL, Li TWH, Yang H, Martínez-Chantar ML, Mato JM, et al. Liverspecific deletion of prohibitin 1 results in spontaneous liver injury, fibrosis, and hepatocellular carcinoma in mice. Hepatology. 2010; 52:2096-108.

18. Zhou T-B, Qin Y-H, Lei F-Y, Huang W-F, Drummen GPC. Prohibitin is associated with antioxidative protection in hypoxia/reoxygenation-induced renal tubular epithelial cell injury. Sci Rep. 2013; 3:3123.

19. Zhou P, Qian L, D'Aurelio M, Cho S, Wang G, Manfredi G, Pickel V, Iadecola C. Prohibitin reduces mitochondrial free radical production and protects brain cells from different 
injury modalities. J Neurosci. 2012; 32:583-92.

20. Theiss AL, Idell RD, Srinivasan S, Klapproth J-M, Jones DP, Merlin D, Sitaraman S V. Prohibitin protects against oxidative stress in intestinal epithelial cells. FASEB J. 2007; 21:197-206.

21. Han J, Yu C, Souza RF, Theiss AL. Prohibitin 1 modulates mitochondrial function of Stat3. Cell Signal. 2014; 26:208695.

22. Sievers C, Billig G, Gottschalk K, Rudel T. Prohibitins are required for cancer cell proliferation and adhesion. PLoS One. 2010; 5:e12735.

23. Chowdhury I, Thompson WE, Welch C, Thomas K, Matthews R. Prohibitin (PHB) inhibits apoptosis in rat granulosa cells (GCs) through the extracellular signalregulated kinase $1 / 2(E R K 1 / 2)$ and the $\mathrm{Bcl}$ family of proteins. Apoptosis. 2013; 18:1513-25.

24. Zhou T-B, Qin Y-H, Lei F-Y, Huang W-F, Drummen GPC. Prohibitin attenuates oxidative stress and extracellular matrix accumulation in renal interstitial fibrosis disease. PLoS One. 2013; 8:e77187.

25. Wang K, Liu C-Y, Zhang X-J, Feng C, Zhou L-Y, Zhao Y, Li P-F. miR-361-regulated prohibitin inhibits mitochondrial fission and apoptosis and protects heart from ischemia injury. Cell Death Differ. 2015; 6:1058-68.

26. Merkwirth C, Martinelli P, Korwitz A, Morbin M, Brönneke HS, Jordan SD, Rugarli EI, Langer T. Loss of prohibitin membrane scaffolds impairs mitochondrial architecture and leads to tau hyperphosphorylation and neurodegeneration. PLoS Genet. 2012; 8:e1003021.

27. Supale S, Thorel F, Merkwirth C, Gjinovci A, Herrera PL, Scorrano L, Meda P, Langer T, Maechler P. Loss of prohibitin induces mitochondrial damages altering $\beta$-cell function and survival and is responsible for gradual diabetes development. Diabetes. 2013; 62:3488-99.

28. Ising $\mathrm{C}$, Koehler S, Brähler S, Merkwirth C, Höhne M, Baris OR, Hagmann H, Kann M, Fabretti F, Dafinger C, Bloch W, Schermer B, Linkermann A, Brüning JC, et al. Inhibition of insulin/IGF-1 receptor signaling protects from mitochondria-mediated kidney failure. EMBO Mol Med. $2015 ; 7: 275-87$

29. Theiss AL, Sitaraman S V. The role and therapeutic potential of prohibitin in disease. Biochim Biophys Acta. 2011; 1813:1137-43.

30. Liu T, Tang H, Lang Y, Liu M, Li X. MicroRNA-27a functions as an oncogene in gastric adenocarcinoma by targeting prohibitin. Cancer Lett. 2009; 273:233-42.

31. Dart DA, Brooke GN, Sita-Lumsden A, Waxman J, Bevan CL. Reducing prohibitin increases histone acetylation, and promotes androgen independence in prostate tumours by increasing androgen receptor activation by adrenal androgens. Oncogene. 2012; 31:4588-98.

32. Qian X, Zhao P, Li W, Shi Z-M, Wang L, Xu Q, Wang M, Liu N, Liu L-Z, Jiang B-H. MicroRNA-26a promotes tumor growth and angiogenesis in glioma by directly targeting prohibitin. CNS Neurosci Ther. 2013; 19:804-12.

33. Barbier-Torres L, Delgado TC, García-Rodríguez JL, Zubiete-Franco I, Fernández-Ramos D, Buqué X, Cano A, Gutiérrez-de Juan V, Fernández-Domínguez I, LopitzOtsoa F, Fernández-Tussy P, Boix L, Bruix J, Villa E, et al. Stabilization of LKB1 and Akt by neddylation regulates energy metabolism in liver cancer. Oncotarget. 2015; 6:2509-23. doi: 10.18632/oncotarget.3191.

34. Ho M-Y, Liang C-M, Liang S-M. MIG-7 and phosphorylated prohibitin coordinately regulate lung cancer invasion/metastasis. Oncotarget. 2015; 6:381-93. doi: 10.18632/oncotarget.2804.

35. Jiang L, Dong P, Zhang Z, Li C, Li Y, Liao Y, Li X, Wu Z, Guo S, Mai S, Xie D, Liu Z, Zhou F. Akt phosphorylates Prohibitin 1 to mediate its mitochondrial localization and promote proliferation of bladder cancer cells. Cell Death Dis. 2015; 6:e1660.

36. Fusaro G, Wang S, Chellappan S. Differential regulation of $\mathrm{Rb}$ family proteins and prohibitin during camptothecininduced apoptosis. Oncogene. 2002; 21:4539-48.

37. Mishra S, Murphy LC, Nyomba BLG, Murphy LJ. Prohibitin: a potential target for new therapeutics. Trends Mol Med. 2005; 11:192-7.

38. Kroemer G, Galluzzi L, Brenner C. Mitochondrial membrane permeabilization in cell death. Physiol Rev. 2007; 87:99-163.

39. Tait SWG, Green DR. Mitochondria and cell death: outer membrane permeabilization and beyond. Nat Rev Mol Cell Biol. Nature Publishing Group, a division of Macmillan Publishers Limited. All Rights Reserved.; 2010; 11:621-32.

40. Martinou J-C, Youle RJ. Mitochondria in apoptosis: Bcl2 family members and mitochondrial dynamics. Dev Cell. NIH Public Access; 2011; 21:92-101.

41. Kasahara A, Scorrano L. Mitochondria: from cell death executioners to regulators of cell differentiation. Trends Cell Biol. 2014; 24:761-70.

42. Ishihara N, Fujita Y, Oka T, Mihara K. Regulation of mitochondrial morphology through proteolytic cleavage of OPA1. EMBO J. 2006; 25:2966-77.

43. Baker MJ, Lampe PA, Stojanovski D, Korwitz A, Anand R, Tatsuta T, Langer T. Stress-induced OMA1 activation and autocatalytic turnover regulate OPA1-dependent mitochondrial dynamics. EMBO J. 2014; 33:578-93.

44. Anand R, Wai T, Baker MJ, Kladt N, Schauss AC, Rugarli E, Langer T. The i-AAA protease YME1L and OMA1 cleave OPA1 to balance mitochondrial fusion and fission. J Cell Biol. 2014; 204:919-29.

45. Ehses S, Raschke I, Mancuso G, Bernacchia A, Geimer S, Tondera D, Martinou J-C, Westermann B, Rugarli EI, Langer T. Regulation of OPA1 processing and mitochondrial fusion by m-AAA protease isoenzymes and OMA1. J Cell Biol. 2009; 187:1023-36.

46. Head B, Griparic L, Amiri M, Gandre-Babbe S, van der Bliek AM. Inducible proteolytic inactivation of OPA1 
mediated by the OMA1 protease in mammalian cells. J Cell Biol. 2009; 187:959-66.

47. Quirós PM, Ramsay AJ, Sala D, Fernández-Vizarra E, Rodríguez F, Peinado JR, Fernández-García MS, Vega JA, Enríquez JA, Zorzano A, López-Otín C. Loss of mitochondrial protease OMA1 alters processing of the GTPase OPA1 and causes obesity and defective thermogenesis in mice. EMBO J. 2012; 31:2117-33.

48. Czabotar PE, Lessene G, Strasser A, Adams JM. Control of apoptosis by the BCL-2 protein family: implications for physiology and therapy. Nat Rev Mol Cell Biol. 2014; 15:49-63.

49. Moldoveanu T, Follis AV, Kriwacki RW, Green DR. Many players in BCL-2 family affairs. Trends Biochem Sci. 2014; 39:101-11.

50. Wei MC, Zong WX, Cheng EH, Lindsten T, Panoutsakopoulou V, Ross AJ, Roth KA, MacGregor GR, Thompson CB, Korsmeyer SJ. Proapoptotic BAX and BAK: a requisite gateway to mitochondrial dysfunction and death. Science. 2001; 292:727-30.

51. De Miguel D, Basáñez G, Sánchez D, Malo PG, Marzo I, Larrad L, Naval J, Pardo J, Anel A, Martinez-Lostao L. Liposomes decorated with Apo2L/TRAIL overcome chemoresistance of human hematologic tumor cells. Mol Pharm. American Chemical Society; 2013; 10:893-904.

52. Gozzelino R, Sole C, Llecha N, Segura MF, Moubarak RS, Iglesias-Guimarais V, Perez-Garcia MJ, Reix S, Zhang J, Badiola N, Sanchis D, Rodriguez-Alvarez J, Trullas R, Yuste VJ, et al. BCL-XL regulates TNF-alpha-mediated cell death independently of NF-kappaB, FLIP and IAPs. Cell Res. 2008; 18:1020-36.

53. Zhou Q, Snipas S, Orth K, Muzio M, Dixit VM, Salvesen GS. Target protease specificity of the viral serpin CrmA. Analysis of five caspases. J Biol Chem. 1997; 272:7797800.

54. Merino R, Ding L, Veis DJ, Korsmeyer SJ, Nuñez G. Developmental regulation of the $\mathrm{Bcl}-2$ protein and susceptibility to cell death in B lymphocytes. EMBO J. 1994; 13:683-91.

55. Sánchez-Quiles V, Santamaría E, Segura V, Sesma L, Prieto J, Corrales FJ. Prohibitin deficiency blocks proliferation and induces apoptosis in human hepatoma cells: molecular mechanisms and functional implications. Proteomics. 2010; 10:1609-20.

56. Kowno M, Watanabe-Susaki K, Ishimine H, Komazaki S, Enomoto K, Seki Y, Wang YY, Ishigaki Y, Ninomiya N, Noguchi TK, Kokubu Y, Ohnishi K, Nakajima Y, Kato K, et al. Prohibitin 2 regulates the proliferation and lineagespecific differentiation of mouse embryonic stem cells in mitochondria. PLoS One. 2014; 9:e81552.

57. Sripathi SR, He W, Atkinson CL, Smith JJ, Liu Z, Elledge BM, Jahng WJ. Mitochondrial-nuclear communication by prohibitin shuttling under oxidative stress. Biochemistry. $2011 ; 50: 8342-51$.
58. Browman DT, Hoegg MB, Robbins SM. The SPFH domain-containing proteins: more than lipid raft markers. Trends Cell Biol. 2007; 17:394-402.

59. Zheng H, Lu GM. Reduction of prohibitin expression contributes to left ventricular hypertrophy via enhancement of mitochondrial reactive oxygen species formation in spontaneous hypertensive rats. Free Radic Res. 2015; 49:164-74.

60. Ye J, Li J, Xia R, Zhou M, Yu L. Prohibitin (PHB) protects proximal tubule epithelial cells against oxidative injury through mitochondrial pathways. Free Radic Res. 2015; 1-39.

61. Bourges I, Ramus C, Mousson de Camaret B, Beugnot R, Remacle C, Cardol P, Hofhaus G, Issartel J-P. Structural organization of mitochondrial human complex I: role of the ND4 and ND5 mitochondria-encoded subunits and interaction with prohibitin. Biochem J. 2004; 383:491-9.

62. Tsutsumi T, Matsuda M, Aizaki H, Moriya K, Miyoshi H, Fujie H, Shintani Y, Yotsuyanagi H, Miyamura T, Suzuki T, Koike K. Proteomics analysis of mitochondrial proteins reveals overexpression of a mitochondrial protein chaperon, prohibitin, in cells expressing hepatitis $\mathrm{C}$ virus core protein. Hepatology. 2009; 50:378-86.

63. Nijtmans LG, de Jong L, Artal Sanz M, Coates PJ, Berden JA, Back JW, Muijsers AO, van der Spek H, Grivell LA. Prohibitins act as a membrane-bound chaperone for the stabilization of mitochondrial proteins. EMBO J. EMBO Press; 2000; 19:2444-51.

64. Jiang $\mathrm{X}$, Jiang $\mathrm{H}$, Shen $\mathrm{Z}$, Wang $\mathrm{X}$. Activation of mitochondrial protease OMA1 by Bax and Bak promotes cytochrome c release during apoptosis. Proc Natl Acad Sci U S A. 2014; 111:14782-7.

65. Alaimo A, Gorojod RM, Beauquis J, Muñoz MJ, Saravia F, Kotler ML. Deregulation of mitochondria-shaping proteins Opa-1 and Drp-1 in manganese-induced apoptosis. PLoS One. 2014; 9:e91848.

66. Scorrano L, Ashiya M, Buttle K, Weiler S, Oakes SA, Mannella CA, Korsmeyer SJ. A distinct pathway remodels mitochondrial cristae and mobilizes cytochrome c during apoptosis. Dev Cell. 2002; 2:55-67.

67. Yamaguchi R, Lartigue L, Perkins G, Scott RT, Dixit A, Kushnareva Y, Kuwana T, Ellisman MH, Newmeyer DD. Opa1-mediated cristae opening is Bax/Bak and BH3 dependent, required for apoptosis, and independent of Bak oligomerization. Mol Cell. 2008; 31:557-69.

68. Ma SB, Nguyen TN, Tan I, Ninnis R, Iyer S, Stroud DA, Menard M, Kluck RM, Ryan MT, Dewson G. Bax targets mitochondria by distinct mechanisms before or during apoptotic cell death: a requirement for VDAC2 or Bak for efficient Bax apoptotic function. Cell Death Differ. 2014; 21:1925-35.

69. Piñon JD, Labi V, Egle A, Villunger A. Bim and Bmf in tissue homeostasis and malignant disease. Oncogene. 2008; 27 Suppl 1:S41-52. 
70. Ploner C, Kofler R, Villunger A. Noxa: at the tip of the balance between life and death. Oncogene. 2008; 27 Suppl 1:S84-92.

71. Strasser A, Cory S, Adams JM. Deciphering the rules of programmed cell death to improve therapy of cancer and other diseases. EMBO J. 2011; 30:3667-83.

72. Oda E, Ohki R, Murasawa $H$, Nemoto J, Shibue $T$, Yamashita T, Tokino T, Taniguchi T, Tanaka N. Noxa, a BH3-only member of the Bcl-2 family and candidate mediator of p53-induced apoptosis. Science. 2000; 288:1053-8.

73. Chen L, Willis SN, Wei A, Smith BJ, Fletcher JI, Hinds MG, Colman PM, Day CL, Adams JM, Huang DCS. Differential targeting of prosurvival Bcl-2 proteins by their BH3-only ligands allows complementary apoptotic function. Mol Cell. 2005; 17:393-403.

74. Shibue T, Suzuki S, Okamoto H, Yoshida H, Ohba Y, Takaoka A, Taniguchi T. Differential contribution of Puma and Noxa in dual regulation of p53-mediated apoptotic pathways. EMBO J. 2006; 25:4952-62.

75. Mishra S, Ande SR, Nyomba BLG. The role of prohibitin in cell signaling. FEBS J. 2010; 277:3937-46.

76. Rajalingam K, Wunder C, Brinkmann V, Churin Y, Hekman M, Sievers C, Rapp UR, Rudel T. Prohibitin is required for Ras-induced Raf-MEK-ERK activation and epithelial cell migration. Nat Cell Biol. 2005; 7:837-43.

77. Kim DK, Kim HS, Kim A-R, Jang GH, Kim HW, Park YH, Kim B, Park YM, Beaven MA, Kim YM, Choi WS. The scaffold protein prohibitin is required for antigen-stimulated signaling in mast cells. Sci Signal. 2013; 6:ra80.

78. Chiu C-F, Ho M-Y, Peng J-M, Hung S-W, Lee W-H, Liang C-M, Liang S-M. Raf activation by Ras and promotion of cellular metastasis require phosphorylation of prohibitin in the raft domain of the plasma membrane. Oncogene. 2013; 32:777-87.

79. Chowdhury I, Thompson WE, Thomas K. Prohibitins role in cellular survival through Ras-Raf-MEK-ERK pathway. J Cell Physiol. 2014; 229:998-1004.

80. Kuramori C, Azuma M, Kume K, Kaneko Y, Inoue A, Yamaguchi Y, Kabe Y, Hosoya T, Kizaki M, Suematsu M, Handa H. Capsaicin binds to prohibitin 2 and displaces it from the mitochondria to the nucleus. Biochem Biophys Res Commun. 2009; 379:519-25.

81. Sato S, Murata A, Orihara T, Shirakawa T, Suenaga K, Kigoshi H, Uesugi M. Marine natural product aurilide activates the OPA1-mediated apoptosis by binding to prohibitin. Chem Biol. 2011; 18:131-9.

82. Polier G, Neumann J, Thuaud F, Ribeiro N, Gelhaus C, Schmidt H, Giaisi M, Köhler R, Müller WW, Proksch P, Leippe M, Janssen O, Désaubry L, Krammer PH, et al. The natural anticancer compounds rocaglamides inhibit the RafMEK-ERK pathway by targeting prohibitin 1 and 2. Chem Biol. 2012; 19:1093-104.

83. Ribeiro N, Thuaud F, Bernard Y, Gaiddon C, Cresteil T,
Hild A, Hirsch EC, Michel PP, Nebigil CG, Désaubry L. Flavaglines as potent anticancer and cytoprotective agents. J Med Chem. 2012; 55:10064-73.

84. Caro-Maldonado A, Tait SWG, Ramírez-Peinado S, Ricci J-E, Fabregat I, Green DR, Muñoz-Pinedo C. Glucose deprivation induces an atypical form of apoptosis mediated by caspase- 8 in Bax-, Bak-deficient cells. Cell Death Differ. 2010; 17:1335-44.

85. Peitz M, Pfannkuche K, Rajewsky K, Edenhofer F. Ability of the hydrophobic FGF and basic TAT peptides to promote cellular uptake of recombinant Cre recombinase: a tool for efficient genetic engineering of mammalian genomes. Proc Natl Acad Sci U S A. 2002; 99:4489-94.

86. Eldering E, Spek CA, Aberson HL, Grummels A, Derks IA, de Vos AF, McElgunn CJ, Schouten JP. Expression profiling via novel multiplex assay allows rapid assessment of gene regulation in defined signalling pathways. Nucleic Acids Res. 2003; 31:e153. 